\title{
The value of public labour market information: the case of dispersed predictions
}

Citation for published version (APA):

Borghans, L. (1991). The value of public labour market information: the case of dispersed predictions. Researchcentrum voor Onderwijs en Arbeidsmarkt, Faculteit der Economische Wetenschappen. ROA Research Memoranda No. 2E https://doi.org/10.26481/umaror.199102E

Document status and date:

Published: 01/01/1991

DOI:

10.26481/umaror.199102E

Document Version:

Publisher's PDF, also known as Version of record

\section{Please check the document version of this publication:}

- A submitted manuscript is the version of the article upon submission and before peer-review. There can be important differences between the submitted version and the official published version of record.

People interested in the research are advised to contact the author for the final version of the publication, or visit the DOI to the publisher's website.

- The final author version and the galley proof are versions of the publication after peer review.

- The final published version features the final layout of the paper including the volume, issue and page numbers.

Link to publication

\footnotetext{
General rights rights.

- You may freely distribute the URL identifying the publication in the public portal. please follow below link for the End User Agreement:

www.umlib.nl/taverne-license

Take down policy

If you believe that this document breaches copyright please contact us at:

repository@maastrichtuniversity.nl

providing details and we will investigate your claim.
}

Copyright and moral rights for the publications made accessible in the public portal are retained by the authors and/or other copyright owners and it is a condition of accessing publications that users recognise and abide by the legal requirements associated with these

- Users may download and print one copy of any publication from the public portal for the purpose of private study or research.

- You may not further distribute the material or use it for any profit-making activity or commercial gain

If the publication is distributed under the terms of Article $25 \mathrm{fa}$ of the Dutch Copyright Act, indicated by the "Taverne" license above, 
THE VALUE OF PUBLIC LABOUR MARKET

INFORMATION: THE CASE OF DISPERSED

PREDICTIONS

ROA-RM-1991\2E

L. Borghans

RESEARCH CENTRE FOR EDUCATION AND LABOUR MARKET

Faculty of Economic Sciences

Rijksuniversiteit Limburg

Maastricht, February 1991 
CIP-GEGEVENS KONINKLIJKE BIBLIOTHEEK, DEN HAAG

Borghans, L.

The value of public labour market information: the case of dispersed predictions / L. Borhans. Maastricht : Research Centre for Education and Labour Market, Faculty of Economic Sciences, Rijksuniversiteit Limburg. - (Report / Research Centre for Education and Labour Market, ISSN 0922-8098; 1991/2E)

ISBN 90-5398-004-0 in spiraalband

Trefw.: arbeidsmartkt ; toekomst 


\section{CONTENTS}

1. INTRODUCTION 1

2. A PARTIAL LABOUR MARKET MODEL 3

3. GENERAL AND INDIVIDUAL PREDICTIONS 5

4. THE COSTS OF PREDICTION ERRORS 8

4.1 General predictions 8

$\begin{array}{ll}4.2 & \text { Individual predictions } \\ 4.3 & 11\end{array}$

4.3 Individual weights, prediction error and the stability of the market 12

5. ADDITIONAL LABOUR MARKET INFORMATION 15

$\begin{array}{lll}5.1 & \text { The usage of information } & 16\end{array}$

5.2 Welfare effects of additional labour market information 21

6. OVERVALUATION OF THE PUBLIC PREDICTION 25

7. CONCLUSIONS 29

$\begin{array}{ll}\text { REFERENCES } & 31\end{array}$

$\begin{array}{ll}\text { APPENDIX A } & 32\end{array}$

$\begin{array}{ll}\text { APPENDIX B } & 33\end{array}$ 


\begin{abstract}
This paper investigates the welfare effects on the labour market caused by the provision of a public labour market prediction. The literature on this subject shows that such a public prediction will improve students' own predictions, what will lead to better anticipations and therefore to a stabilisation of the labour market. Students' own predictions are, however, mostly assumed all to be equal. In this paper students' predictions about the future labour market are dispersed. A public prediction leads, in this case, not only to better individual predictions but will also decrease the dispersion. This second factor leads to instability instead of stability.
\end{abstract}

The paper shows that in case of dispersed predictions, public information might indeed lead to more instability of the labour market, but even such an increase of instability is always a welfare improvement. Crucial for this result is the assumption that students correctly estimate the reliability of the public prediction. The paper also shows that if this assumption is released, a public prediction might lead to a decrease of the stability and to a welfare-loss.

I would like to thank Andries de Grip, Paul Ghijsen, Hans Heijke, Marga Peeters and Willy Spanjers for their helpful comments 


\section{INTRODUCTION}

The allocation of human capital to various occupations is hampered by the fact that the choice for a specific specialisation has to be made several years before these specialisations can be productive. The time-lag between investment and production leads to an information problem. Firstly, there might be total unpredictable changes during the years of education and secondly, the optimal predictions might not be available for those people who have to make the investment decision. The first problem of unpredictable changes is a general problem for all types of investments. It has been studied rather extensive by the theory of rational expectations.

The second problem, where people who have to make investment decisions are not able to interpret the information in the right way, while others, who do not have to make an investment decision, are in a better position to do this, is more specific a problem of human capital investments. In a general investment context, investments are made by entrepreneurs, whose specialty it is to predict the future. Investments in human capital, on the other hand, only can be made by students, while entrepreneurs have probably more understanding of the functioning and development of the labour market. Due to the educational system, students are forced to make an investment decision. Furthermore, there is no market mechanism by which individual information is transferred to anybody who needs it. Students have to base their investment decisions on predictions, formed by use of their restricted insight in the way the labour market functions. Future employers might give some information to the student in order to influence their behaviour, but the interest of the student is not always the interest of the employer. Therefore such information without obligation (i.e. without a binding contract) may not automatically be seen as reliable or complete.

An obvious policy to reduce this information problem is the provision by the government of forecasts about the future labour market. One of Freeman's (1971) eight policy implications for education and manpower policy is that 'the existence of lengthy disequilibriums under incomplete adjustment directs attention to the value of manpower forecasts in the labour market. Since career decisions result from a rational consideration of alternatives, students are likely to react favourably to a comprehensive, high quality set of forecasts'. ${ }^{1}$ Freeman's suggestion is that the informational problem students are posed to, will be reduced by a high quality set of forecasts: such forecasts combat the disequilibria on the labour market and are favourably to students. Freeman's policy implication is based on the intuition that more

1. Freeman (1971), p. 229. 
information leads to better decisions and thereby to more stability at the labour market as to a welfare gain.

Studies about the value of public predictions have been carried out by e.g. Hayami and Peterson (1972), Freebairn (1976), Bradford and Kelejian (1977), Turnovski (1978) and Antonovitz and Roe (1986) in another context, while Freebairn and Withers (1979) and Borghans (1990) focus on the value of public labour market information.

All these papers relate the problem of forecast errors to stabilisation theory. Their main argument is that if students decrease their prediction error by use of a public forecast, the supply of labour will become more stable and this leads to a welfare gain similar to gains from stabilisation in studies like Massel (1969).

An implicit simplification of these studies is the assumption that the predictions of the future labour market are equal for every student. Due to this simplification there exists no aggregation problem. Individual prediction errors can directly be related to macro-economic phenomena such as the stability of the market. But more important, this assumption excludes a negative aspect of public forecasts. The prediction error of one individual student will not influence the market stability and an overprediction of some students might compensate for the underprediction of others. A prediction error in a public forecast is more dangerous. It influences everybody in the same direction and will therefore destabilise the market.

Under the assumption that students predictions are dispersed a public forecast will have an additional effect of reducing the dispersion. Students predictions become more correlated and therefore might disturb the market-equilibrium more easily.

The purpose of this paper is to calculate the effects of labour market information in a context of dispersed predictions. Firstly, in section 2 a partial labour market model is introduced, which is the starting-point for the study. In section 3 the prediction errors (and their interdependence) are defined. The introduction of dispersed predictions makes it necessary to extent the usual model with an explicit formulation about the usage of public information by students. In former models the old prediction error simply is replaced by the new one, without describing how this new error comes about. The welfare costs (or gains) of these prediction errors are calculated in section 4, while the effects of an additional public prediction are calculated in section 5 . Since the usage of this public information has to be modelled explicitly, the question what happens in the case students do not use this information optimally becomes important. This is the subject of section 6 . Finally some conclusions are drawn. 


\section{A PARTIAL LABOUR MARKET MODEL}

This section provides a simple partial labour market model (illustrated in figure I). On this market there is only one type of labour. Students can offer their labour at this market only after they finished an educational course, which is specific for this labour market segment. Other labour market segments also have such educational requirements, so it is impossible to change to another segment after the educational choice has been made. Since the course will take some years, the students have to make their decisions about on which market they will offer their labour some years in advance.

Figure I: A partial labour market model

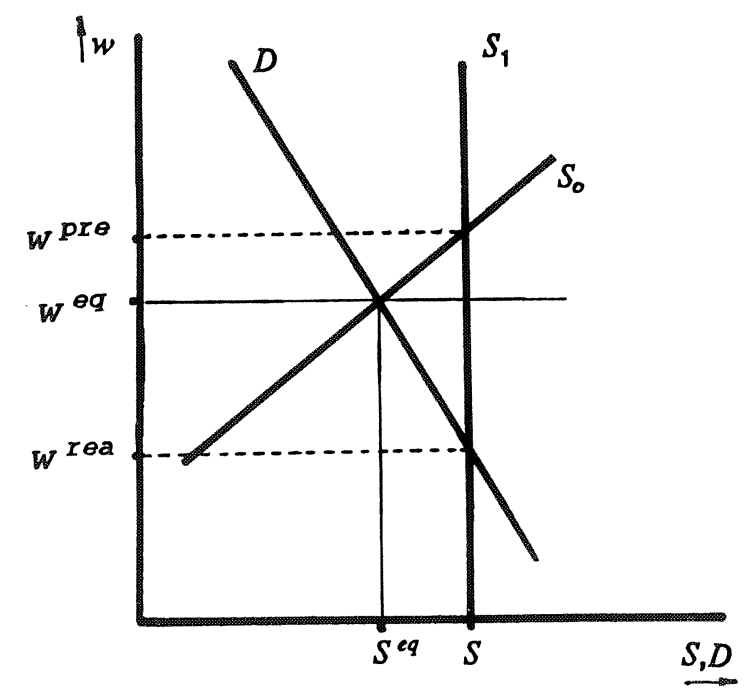

In figure $\mathrm{I}$ this is illustrated by two supply curves. $S_{0}$ represents the supply before the educational decision has been made (the long run supply function). The supply only depends on the wage. $S_{1}$ represents the supply after this decision (the short run supply function).

(1) $S_{0}=C_{s}+\beta_{s} w_{0}^{\text {pre }} \quad$ with $\beta_{s}>0$

(2) $s_{1}=s_{0}$

Supply function (1) can be interpreted as a ordered set of reservation wages $\left(w_{i}^{\text {res }}\right)$. To increase supply, the predicted wage has to increase. Due to such an increase the wage will exceed the reservation wage of some marginal students, who will therefore decide to enter the market.

Because the educational course has to be chosen several years in advance, the supply is based 
on predicted wages $\left(w_{0}^{p r e}\right)$ instead of realised wages. After the educational choice has been made, the supply is completely inelastic. The use of $w_{0}^{\text {pre }}$ implicitly assumes the existence of a prediction which is the same for every student. In section 3 the dispersion of the predictions is introduced.

On the demand side information problems do not occur. Demand decisions are taken in accordance with the realised wage $\left(w^{\text {rea }}\right)$, i.e. the market is completely cleared by wages and employers do not face adjustment costs.

(3) $D=C_{D}+\beta_{D} w^{\text {rea }} \quad$ with $\beta_{D}<0$

and thus, for demand to equal supply,

(4) $S_{1}=D$

The realised wage is implicitly defined by $(2),(3)$ en $(4)$, i.e. the wage that clears the market. The equilibrium wage $w^{e q}$ is defined as the wage that would clear the market if the prediction of every student equals the realisation. ${ }^{2}$ If the equilibrium wage is realised:

(5) $w^{\text {pre }}=w^{\text {rea }}=w^{e q}=\frac{C_{D}-C_{S}}{\beta_{S}-\beta_{D}}$

If this equality between prediction and realisation does not hold, then:

(6) $w^{\text {rea }}=\frac{C_{S}-C_{D}+\beta_{S} w^{\text {pre }}}{\beta_{D}}$

and because $C_{S}-C_{D}=w^{e q}\left(\beta_{D}-\beta_{S}\right)$ (equation 5)

(7) $w^{\text {rea }}=w^{\text {eq }}-\frac{\beta_{s}}{\beta_{D}}\left(w^{\text {eq }}-w^{\text {pre }}\right)$

This equation shows that an underestimation of the equilibrium wage leads to an excess realised wage and v.v., dependent on the parameters of the supply and demand function. If students expectations are too high, too many will enter the market, what will lead to wages below the equilibrium level.

2. In a situation with dispersed prediction, as introduced in section 3 , this implies that the equilibrium wage might be realised although there is not a situation of equilibrium. Without being correct, predictions might compensate for each other. In such a situation non-equilibrium predictions generate the equilibrium wage. 


\section{GENERAL AND INDIVIDUAL PREDICTIONS}

In the model of last section the realised wage depends on the equilibrium wage and on the predicted wage. The prediction, however, does not need to be the same for every student. Surveys indicate a considerable dispersion of students' expectations (e.g. Kodde, 1985, p. 5556). Students will have different information relevant for predicting the future situation, but most important, students will have different interpretations on the information. The basic assumption of rational expectations, that every student knows the true model, will be rather unrealistic and unfruitful in a situation such as the labour market, which is very complex and at which the agents, i.e. the students, are unexperienced. Every student has his own 'theory' of how the labour market develops. Students' predictions, on the other hand, influence each other. Similar sources are used and personal views are discussed.

In this section the model of section 3 is extended with some assumptions about the distribution of the predictions. Each individual prediction is indicated by:

(8) $P_{i}$ with $\mathbb{E}\left\{P_{i} \mid w^{e q}\right\}=w^{e q}$

This definition is general in the sense that it does not presume a certain prediction-mechanism, like myopic or partial adjustment predictions, but only requires these predictions to be 'correct in average'.

The definition excludes however the rational expectations type of prediction error. The future equilibrium wage is assumed to be determined, and the prediction is stochastic, while a rational expectations forecast error typically assumes the prediction to be determined by the available information, but the future to be stochastic.

A second remark concerns the global character of the definition. The expectation operator is taken only conditional on the equilibrium wage. Other information available to policy makers might make it possible to predict the forecast errors of students. This information makes it possible to refine the policy instrument, e.g. government might decide to publish a forecast only in case of an overprediction.

The formulation of (8) is chosen in order to study the effect of a public labour market forecast per se, i.e. 'before' policy has taken into account the exact situation the labour market is at.

Furthermore the assumption is made that $w^{\text {eq }}-w^{\text {rea }}$ is unpredictable for students. Students themselves are not able to predict the forecasts of others. Therefore, their prediction of $w^{\text {eq }}$ in 
(8) can also be seen as a prediction of $w^{\text {rea }}$.

For simplicity the assumption is made that every student predicts the future wage with the same precision.

(9) $\operatorname{VAR}\left\{P_{i} \mid w^{\text {eq }}\right\}=\sigma_{P}^{2} \forall i$ or

(10) $V A R\left\{P_{i} \mid w^{\text {rea }}\right\}=\sigma_{\bar{P}}^{2} \quad \forall i$

In this paper variances conditioned on the equilibrium wage are indicated without bar, while variances conditioned on realised wage are indicated with a bar.

Furthermore it is assumed that the covariance between the predictions of every two students is the same. This can be expressed by defining the general (or average) prediction:

(11) $G=\frac{1}{n} \sum P_{i}$

and rewriting

(12) $P_{i}=G+I_{i}$

i.e. every student $\mathrm{i}$ has a prediction $\boldsymbol{P}_{\boldsymbol{i}}$ which consists of a general part $\mathrm{G}$ and an individual part $I_{i}$. It is assumed that $n$, the number of students, is large enough to neglect the influence of one student on $G$.

The prediction variable of the labour market model of previous section ( $w^{\text {pre }}$ ) must be seen as the average predicted wage (G). At the market only the total supply matters, and total supply only depends on aggregated predictions (which are equivalent to average predictions in a linear model like this) since the effect of students with predictions higher than average will compensate the effect of students with predictions less than average.

The assumption is made that the individual part of the prediction-error does not correlate with the general prediction error or with the individual part of others:

(13) $\mathbb{E}\left\{I_{i} \mid I_{j}, G\right\}=0 \quad \forall i \neq j$

(14) $E\left\{G \mid w^{e q}\right\}=w^{e q}$

and by calling

(15) $\operatorname{VAR}\left\{I_{i} \mid w^{e q\}}=\sigma_{I}^{2} \quad \forall i\right.$ 
it follows that

(16) $\operatorname{VAR}\left\{G \mid w^{e q}\right\}=\sigma_{G}^{2}=\sigma_{P}^{2}-\sigma_{I}^{2}$

Finally, there exists an additional labour market prediction $\mathrm{N}$, which is independent of the individual components but which might be correlated with the general prediction.

(17) $E\left\{N \mid w^{e q}\right\}=w^{e q}$

(18) $\operatorname{VAR}\left\{N \mid w^{e q}\right\}=\sigma_{N}^{2}$

with

(19) $\operatorname{CoV}\{N, G\}=\sigma_{N G}$

(20) $\left.\operatorname{COV} N_{,} I_{i}\right\}=0$

This additional prediction represents the information of the government or an institution, published with the purpose to improve the match between schooling and work.

Table 1 summarises the covariances between the general prediction, the predictions of two students (1 and 2) and the additional prediction.

Table 1: the covariances between the labour market predictions

G

$\begin{array}{lll}P_{1} & P_{2} & N\end{array}$

G

$\sigma_{G}^{2} \quad \sigma_{G}^{2} \quad \sigma_{G}^{2} \quad \sigma_{N G}$

$P_{1}$

$\sigma_{I}^{2}+\sigma_{G}^{2}$

$\sigma_{G}^{2}$

$\sigma_{N G}$

$P_{2}$

$$
\sigma_{I}^{2}+\sigma_{G}^{2} \quad \sigma_{N G}
$$

$N$

$\sigma_{N}^{2}$

All moments defined above refer to the relation between the predictions and the equilibrium or the realisation of the wage and indicate the 'prediction-quality'. To indicate the stability of the market, the variance of the difference between equilibrium and realisation will be used:

(21) $\sigma_{w}^{2}=E\left\{\left(w^{r e a}-w^{e q}\right)^{2}\right\}=E\left\{\left(\frac{\beta_{S}}{-\beta_{D}}\left(G-w^{e q}\right)\right)^{2}\right\}$ 


\section{THE COSTS OF PREDICTION ERRORS}

In the previous sections both a simple labour market model and a definition of dispersed predictions have been introduced. In this section the costs are calculated for both general and individual predictions errors. These costs are by definition opposite to the value of full information. The value of incomplete information can be derived from these calculations by subtracting the costs of prediction errors for and after additional information has been obtained.

To be able to calculate the costs of a prediction error, a measure is needed. As measure for the costs the surplus is taken, i.e.:

$$
\left\{\begin{aligned}
u_{i}\left(a_{i}, w^{\text {rea }}\right) & =w^{\text {rea }}-w_{i}^{\text {res }} & & \text { if } a_{i}=\text { 'enter' } \\
& =w_{i}^{\text {res }}-w^{\text {eq }} & & \text { if } a_{i}=\text { 'not enter' }
\end{aligned}\right.
$$

in which $w_{i}^{\text {res }}$ is the reservation wage of student $i$, i.e. the wage at which $i$ is indifferent between taking the job and not taking the job. Total surplus of the supply-side can be derived by integrating over the suppliers, which leads to the well-known area's in the supply and demand picture.

To avoid double-counting for students who mistakenly do not enter, only the difference $w_{i}^{\text {res }}-w^{e q}$ is added to the surplus of this market. The difference between equilibrium wage and realised wage is assigned to the labour market segment he has entered.

For the demand-side a similar surplus measure is used.

\subsection{General predictions}

Figure II depicts the labour market model in which a general prediction error occurs. In Ila the prediction of the wage is too high while in llb the prediction is too low. 
Figure II: Students welfare in case of a general prediction error

a

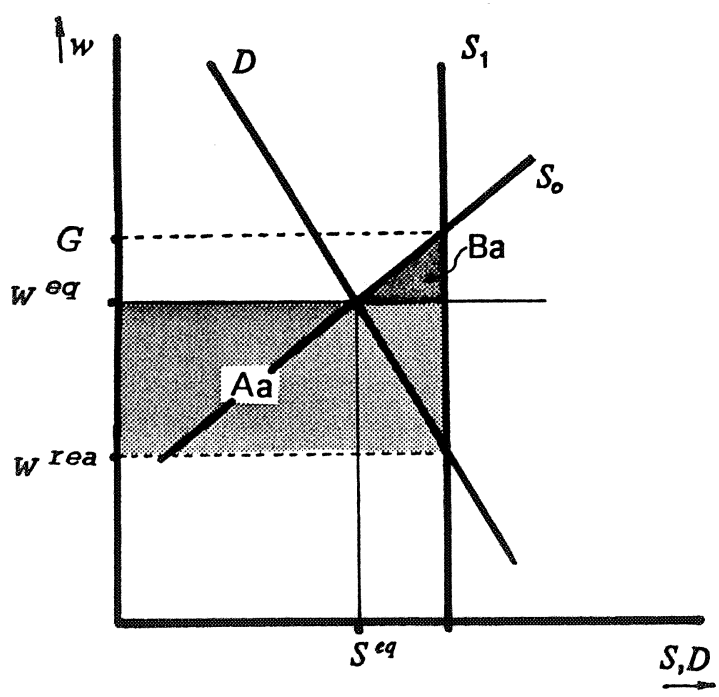

b

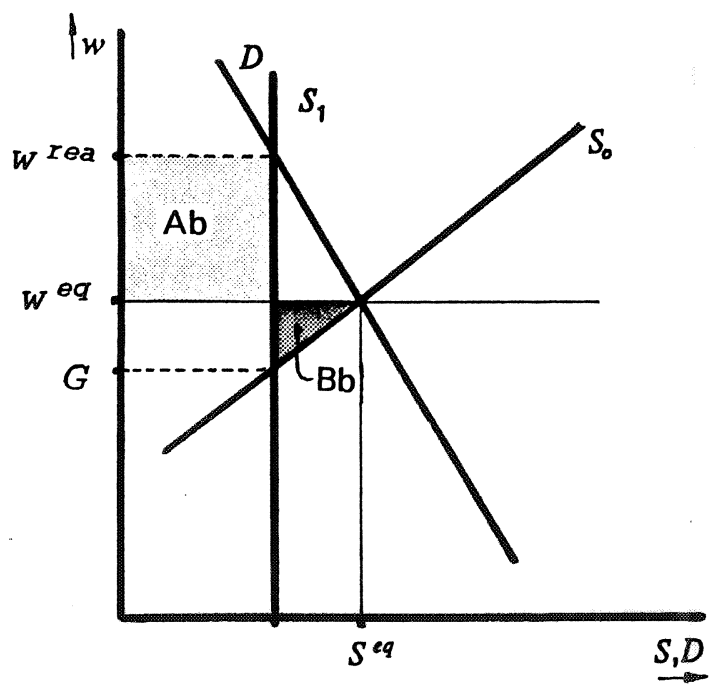

If the prediction of the wage is too high, too many students will choose for this sector and thus realised wage will be lower than equilibrium wage and a welfare loss for the students will occur. This welfare loss consists of the rectangle $A a$, due to the destabilisation of the markets plus an extra allocation welfare loss (triangle $\mathrm{Ba}$ ) for those students who, compared with the equilibrium situation, chose the wrong course. ${ }^{3}$ In the case the prediction is too low the opposite reasoning leads to a welfare gain $A b$, minus the costs of students who, wrongly, did not enter (triangle $\mathrm{Bb}$ ). By taking into account the stochastic nature of the expectation error $\Delta w=G-w^{e q}$, with density $F_{G}$, the expected welfare effect for students can be calculated:

(23)

$$
\begin{aligned}
W_{S t}\left(\sigma_{G}^{2}\right) & =\int_{-\infty}^{\infty}\left[S\left(w^{\text {pre }}\right)\left(w^{\text {rea }}-w^{e q}\right)-\frac{1}{2}\left(S\left(w^{\text {pre }}-S\left(w^{e q}\right)\right) \Delta w\right] \mathrm{d} F_{G}(\Delta w)\right. \\
& =\int_{-\infty}^{\infty}\left[\beta_{S}\left(w^{e q}+\Delta w\right) \cdot\left(-\frac{\beta_{S}}{-\beta_{D}} \Delta w\right)-\frac{1}{2} \beta_{S} \Delta w^{2}\right] \mathrm{d} F_{G}(\Delta w) \\
& =\int_{-\infty}^{\infty}-\beta_{S} w^{e q} \frac{\beta_{S}}{-\beta_{D}} \Delta w \mathrm{~d} F_{G}(\Delta w)+\int_{-\infty}^{\infty}\left(-\beta_{S} \frac{\beta_{S}}{-\beta_{D}}-\frac{1}{2} \beta_{S}\right) \Delta w^{2} \mathrm{~d} F_{G}(\Delta w) \\
& =-\left(\frac{\beta_{S}^{2}}{-\beta_{D}}+\frac{1}{2} \beta_{S}\right) \sigma_{G}^{2}
\end{aligned}
$$

3. See Borghans (1990) for the division between stabilisation and allocation effects of predictions errors. 
A similar calculation can be made for the expected welfare effects for the employers, i.e. the demand-side of the market. This is illustrated in figure IIla and IIIb.

Figure III: Employers welfare in case of a general prediction error

a

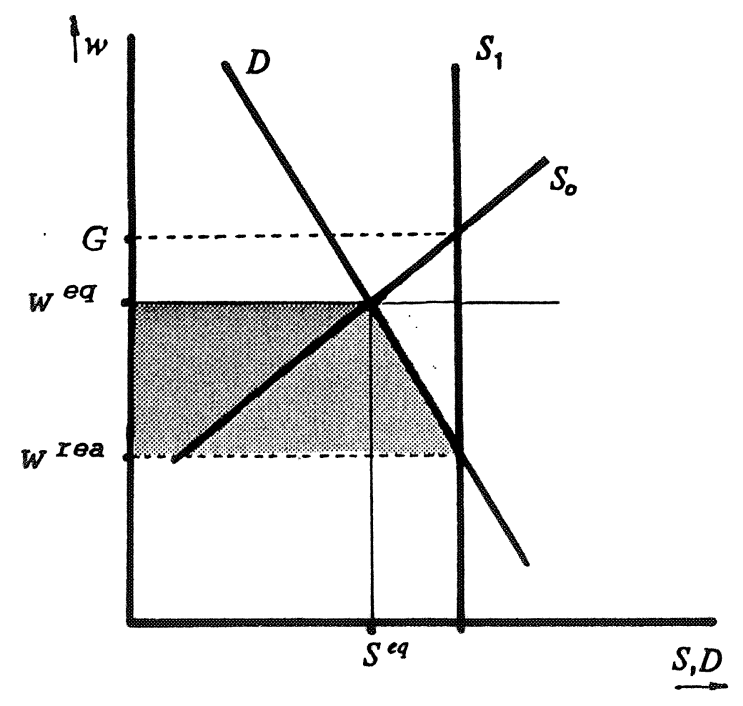

b

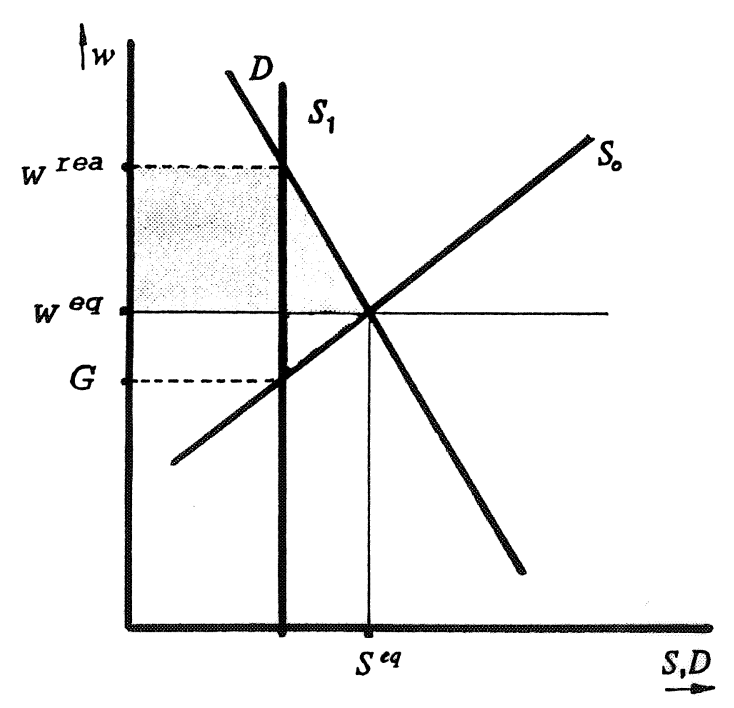

In case of an underprediction the supply of employees will be too small, which causes the wage to rise. The employer will have to pay extra wage for the workers but will reduce the number of workers, which reduces his extra costs. In case of an overprediction supply will be greater than in equilibrium which causes the wages to fall so the employer will have to pay a lower wage. Furthermore, he will increase the number of workers at this lower wage. The expected welfare gain for the employers is:

$$
\begin{aligned}
W_{E m p}\left(\sigma_{G}^{2}\right) & =\int_{-\infty}^{\infty} \frac{1}{2}\left(w^{e q}-w^{r e q}\right)\left(S\left(w^{\text {eq }}\right)+S\left(w^{\text {req }}\right)\right) \mathrm{d} F_{G}(\Delta w) \\
& =\int_{-\infty}^{\infty} S\left(w^{e q}\right) \frac{\beta_{S}}{-\beta_{D}} \Delta w \mathrm{~d} F_{G}(\Delta w)+\int_{-\infty}^{\infty} \frac{1}{2} \frac{\beta_{S}}{-\beta_{D}} \beta_{S} \Delta w^{2} \mathrm{~d} F_{G}(\Delta w) \\
& =\frac{1}{2} \frac{\beta_{S}^{2}}{-\beta_{D}} \sigma_{G}^{2}
\end{aligned}
$$

Due to the fact that the employers will adjust their working force to the fluctuating supply they are able to gain from these prediction errors. This result is similar to the gains from price instability found by Waugh (1944). 


\subsection{Individual predictions}

The welfare losses calculated in last section are not the only costs students face. Due to the fact that predictions are dispersed some students will make a prediction better than the general prediction while others make a worse prediction. The costs of a worse prediction are not fully compensated by the gain of a better prediction, as is shown in figure IV.

The figure illustrates the situation of an prediction error which deviates from the general prediction error. The welfare effect is illustrated as if everybody made this individual prediction error, which is impossible due to the definition of individual prediction error. In the calculations this is corrected by multiplying the welfare loss by the (small) fraction that actually made this individual prediction error. Therefore it is also assumed in the figure that the realised wage is not affected by this individual prediction error. Essential in the derivation is that the individual prediction errors do not correlate with the reservation wage, i.e. the position on the supply curve does not influence the individual prediction error.

Figure IV: Students welfare in case of an individual prediction error

a

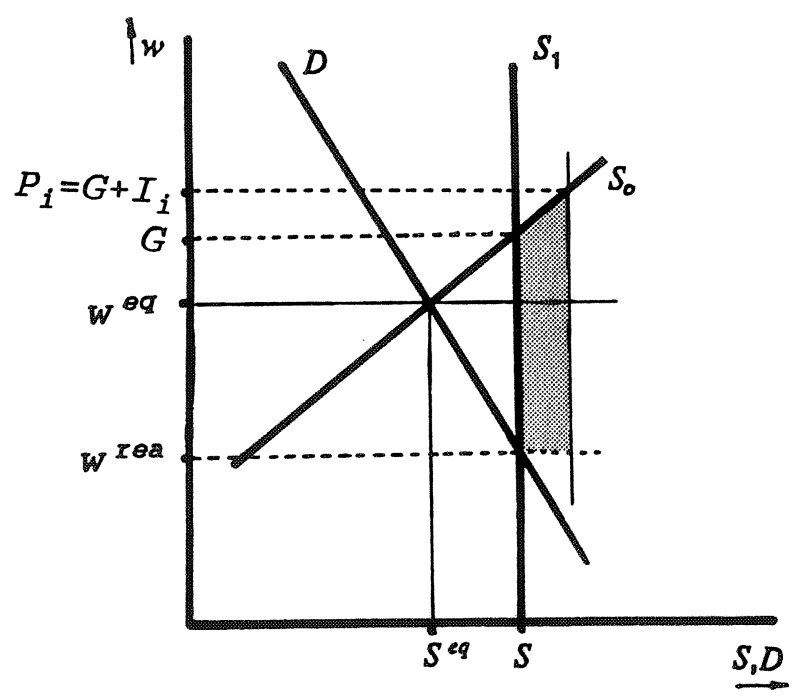

b

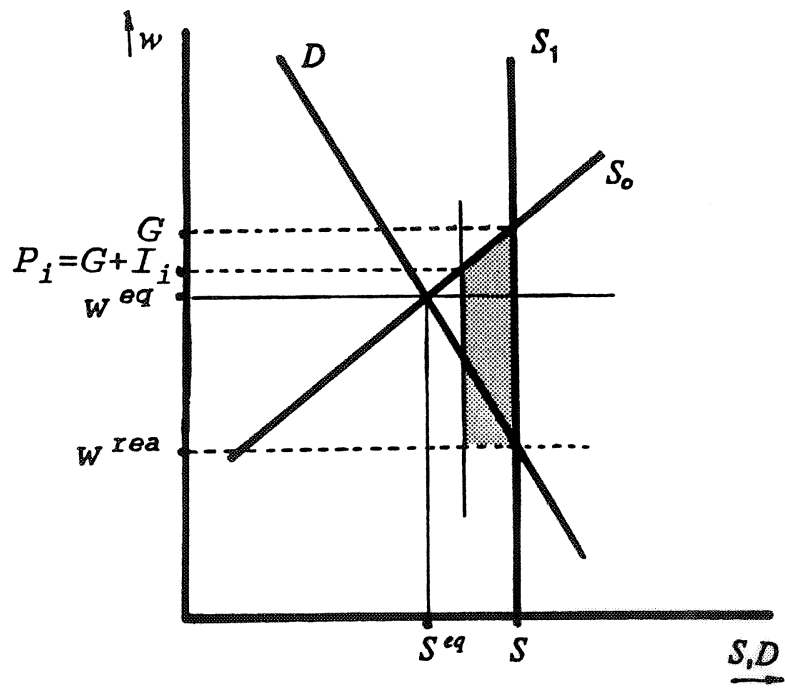

Using the distribution $F_{I}$ of individual prediction errors $\left(\Delta w_{i}=P_{i}-G=I_{i}\right)$, the welfare loss of individual prediction errors can be calculated: 
(25) $W_{S t}\left(\sigma_{I}^{2}\right)=\int_{-\infty}^{\infty} \frac{1}{2} \Delta w_{i}\left(S\left(w^{e q}\right)-S\left(w^{p r e d}\right)\right) \mathrm{d} F_{I}\left(\Delta w_{i}\right)$

$$
\begin{aligned}
& =\int_{-\infty}^{\infty}-\frac{1}{2} \beta_{s}\left(\Delta w_{i}\right)^{2} d F_{I}\left(\Delta w_{i}\right) \\
& =-\frac{1}{2} \beta_{s} \sigma_{I}^{2}
\end{aligned}
$$

These welfare costs equal the allocation part of students' welfare costs of a general prediction error. Because an individual prediction error does not influence the realised wage, the stability component does not play a part in this calculation.

\subsection{Individual weights, prediction error and the stability of the market}

In the previous sub-sections the welfare-effects of prediction errors have been calculated. These welfare-effects represent costs for certain groups: students, employers or both. A student who has to decide which prediction he should use will, however, not base his decision on welfarearguments of the group he belongs to, but will try to maximise his own welfare.

Therefore, it seems appropriate to assume students will minimise the variance of the prediction error itself, and not a weighted sum of individual and general prediction error. Furthermore, the prediction error that will be relevant for students is the prediction error with respect to the realisation of the wage and not with respect to equilibrium:

(26) $\sigma_{\bar{P}}^{2}=E\left\{\left(P-w^{\text {rea }}\right)^{2}\right\}=\left(\frac{\beta_{S}}{-\beta_{D}}+1\right)^{2} \sigma_{G}^{2}+\sigma_{I}^{2}$

In table 2 the welfare effects of both individual and general prediction errors are summarised. The prediction error with respect to realisation and the stability of the market have been added. 
Table 2: An overview of the welfare effects of prediction errors and the stability of the market

general

prediction error individual

prediction error

ratio*

\section{WELFARE EFFECTS:}

students

$$
-\left(\frac{\beta_{S}^{2}}{-\beta_{D}}+\frac{1}{2} \beta_{S}\right) \sigma_{G}^{2}
$$$$
-\frac{1}{2} \beta_{S} \sigma_{I}^{2}
$$

employers

$$
\frac{1}{2} \frac{\beta_{S}^{2}}{-\beta_{D}} \sigma_{G}^{2}
$$

0

total

$$
-\frac{1}{2}\left(\frac{\beta_{S}^{2}}{-\beta_{D}}+\beta_{S}\right) \sigma_{G}^{2}
$$

$-\frac{1}{2} \beta_{S} \sigma_{I}^{2}$

$\mathrm{F}+1$

\section{$\sigma_{P}^{2}$ (perceived by}

individual students)

$$
-\left(\frac{\beta_{S}}{-\beta_{D}}+1\right)^{2} \sigma_{G}^{2}
$$

$F^{2}+2 F+1$

stability of market

$$
-\left(\frac{\beta_{S}}{-\beta_{D}}\right)^{2} \sigma_{G}^{2}
$$

* $\frac{\beta_{S}}{-\beta_{D}}$ is, for convenience, be abbreviated by $F(F>0)$.

The use of public information will have two consequences, as mentioned in the introduction. Firstly, it will decrease the variance of the prediction error of a student $\sigma_{P}^{2}$. Secondly, it will decrease the individual component and increase the general component of the prediction error. Since, only the general prediction error influences the market both types of errors can not be seen as equal. Both types of errors lead to different welfare costs as shown in last section. To choose an optimal use of the public information it is necessary to balance the advantages of a decrease of the prediction error and the disadvantages of a decrease of the dispersion. The third column of table 2 gives, for students, employers and the total, the relative welfare costs of general prediction errors compared to individual prediction errors.

The ratio between the importance of general and individual prediction errors from the point of 
view of individual students, does not equal the ratio's of the three welfare measures. This indicates that there are some external effects which the student does not take into account.

Firstly, by weighing up the consequences of individual and general prediction errors students do not take into account the (very small) effects their choice has upon other students. On aggregate level these small effects will be, however, substantial. This results in a transfer of (negative) welfare from students to other students.

Secondly, by minimising their prediction error students also cause redistribution between themselves and employers, since employers gain from prediction errors.

Thirdly, students will overvaluate the importance of general prediction errors, because for individual students the difference between their prediction and the realisation is important. They do not take into account that an improvement of the prediction with respect to the equilibrium wage will also lead to a decrease of the gap between equilibrium and realisation. 


\section{ADDITIONAL LABOUR MARKET INFORMATION}

The provision of additional labour market information might be an instrument to lower the average prediction error and thereby to lower the costs of prediction errors. In this section the reduction of prediction error costs due to the provision of additional labour market information, i.e. the value of information, will be calculated.

Last section was addressed to the measurement of the costs of prediction errors. An important conclusion is that individual students relatively overestimate the importance of general prediction errors. In the first part of this section it will be derived to what extent students will use additional labour market information in order to minimise their risk.

Departure of this calculation is the possibility for students to choose to what extent they will use the public information. Mostly, it is assumed that students completely adopt the public prediction and give up their own prediction. ${ }^{4}$ This would be very unrealistic and inefficient. Unrealistic, because it is hard to imagine students completely changing their mind due to public information. In accordance with studies about expectation formation public information will only influence students partially. Since public forecasts will never be infallible it is also rational not to use public information completely. The public forecast contains an error, so other information, like students' own predictions, still has some value. Providing public information might be seen as adding new elements into students' discussion, which generates their expectations.

Students will, however, by deciding the extent of the usage of public information not take into account the three external effects of their decision upon the stability of the market (see section 4), since individual students have no influence on the aggregate market situation.

As noticed in the previous section students will not avoid using public information because this will cause a destabilisation, but they will use public information to a less extent because it appears less reliable. The disadvantages of using public information have the be transformed into a decrease of its quality (measured with respect to the realised wage) before it will influence students behaviour.

The second part of this section is devoted to the consequences this usage of information has upon the welfare of students, employers and on the total welfare and its influence on the

4. Or alternatively, that some students completely adopt the public prediction, while others stick completely to their own prediction, e.g. because they did not receive the public information (Turnovski, 1978). 
stability of the labour market.

\subsection{The usage of information}

The provision of an additional labour market prediction, published by a (governmental) forecasting bureau, gives students the possibility to adjust their expectations about the labour market, on which they will base their decision what school to attend. Since also this additional prediction is not perfect, they do not need to take over the additional prediction completely, but they can form a new prediction by mixing their prediction with the additional prediction. Indicating this new, mixed, prediction with a circumflex this leads to:

(27) $\hat{P}_{i}=\lambda_{1} P_{i}+\lambda_{2} N$

(28) with $\lambda_{1}+\lambda_{2}=1$

Although the decision about this mix is made at an individual level, $\lambda_{1}, \lambda_{2}$ do not contain a subscript $i$. Since the variances of the prediction errors are the same for every student all individual $\lambda$ 's will be equal. Therefore the subscript $i$ can be omitted.

The variance of $\hat{P}_{i}$ can again be split up in a general part and an individual part, both depending on the mixing coefficients $\lambda_{1}$ and $\lambda_{2}$ and the variances of $G, I_{i}$ and $N$. Students will, according to the results of last section, not be interested in minimising the welfare costs of $\sigma_{\hat{p}}^{2}$. Individual students do want to minimise their prediction error, as defined in last section. Minimising this prediction error is equivalent to minimising the variance of the difference between the prediction $\hat{P}_{i}$ and the realised wage (not the equilibrium wage). Students, will choose weight $\lambda_{1}$, such that the resulting prediction error is minimal. This $\lambda_{1}$, from a students point of view, is thus a function of the prediction errors of the two initial sources, and of their covariance with respect to the realised wage.

The variance of this difference between prediction and realisation depends, however, on the extent of usage of the several sources of information. If an information source is used to a greater extent, its influence on the realised wage will be bigger and this will influence the reliability of all sources, e.g. because $w^{\text {rea }}=w^{\text {eq }}-F\left(\lambda_{1} G+\lambda_{2} N-w^{\text {eq }}\right)$ : 
(29) $\left.\sigma_{N}^{2}=E\left(N-w^{r e a}\right)^{2}\right\}$

$$
\begin{aligned}
& =\boldsymbol{E}^{\prime}\left(N-w^{\text {eq }}+F\left(\lambda_{1} G+\lambda_{2} N-w^{\text {eq }}\right)\right)^{2\}} \\
& \left.=\boldsymbol{E}^{2}\left(\left(1+\lambda_{2} F\right)\left(N-w^{\text {eq }}\right)+\lambda_{1} F\left(G-w^{\text {eq }}\right)\right)^{2}\right\} \\
& =\lambda_{1}^{2} F^{2} \sigma_{G}^{2}+\left(1+\lambda_{2} F\right)^{2} \sigma_{N^{2}}^{2}+2\left(1+\lambda_{2} F\right) \lambda_{1} F \sigma_{N G}
\end{aligned}
$$

Similar calculations for $\sigma_{\bar{G}}^{2}$ and $\sigma_{\overline{N G}}$ lead to:

(30) $\left(\begin{array}{c}\sigma_{\bar{G}}^{2} \\ \sigma_{\bar{N}}^{2} \\ \sigma_{\bar{N} \bar{G}}\end{array}\right)=\left(\begin{array}{ccc}\left(1+\lambda_{1} F\right)^{2} & \lambda_{2}^{2} F^{2} & 2\left(1+\lambda_{1} F\right) \lambda_{2} F \\ \lambda_{1}^{2} F^{2} & \left(1+\lambda_{2} F\right)^{2} & 2\left(1+\lambda_{2} F\right) \lambda_{1} F \\ \left(1+\lambda_{1} F\right) \lambda_{1} F & \left(1+\lambda_{2} F\right) \lambda_{2} F & \left(1+\lambda_{1} F\right)\left(1+\lambda_{2} F\right)+\lambda_{1} \lambda_{2} F^{2}\end{array}\right)\left(\begin{array}{c}\sigma_{G}^{2} \\ \sigma_{N}^{2} \\ \sigma_{N G}\end{array}\right)$

The implication of these formula's is that the extent of usage of both $\mathrm{N}$ and $P_{i}=G+I_{i}$ affects the reliability of the predictions. Since students will use the predictions depending on their reliability, a simultaneous dependency occurs between the reliability of $\mathrm{N}$ and $\mathrm{G}$ and its usage.

The decision to use the additional labour market information is taken at an individual level. From this point of view the extent of usage of the additional prediction will not affect its reliability, since the decision of only one person does not have any effects on aggregated level. A student, thus, will not take into account these effects as he optimises the extent of usage. He will take the reliability of both his own prediction and the additional prediction as given.

In formula (31) the prediction error, that will be minimised by the students is calculated. Because a student takes the variances of the predictions as given, the $\lambda$ 's that occur in this part of the equation have been indicated by a tilde $\left(\tilde{\lambda}_{1}, \tilde{\lambda}_{2}\right)$. (31) will be minimised with respect to $\lambda_{1}, \lambda_{2}$ without tilde only.

(31) $\sigma_{P}^{2}=E\left\{\left(P-w^{r e a}\right)^{2}\right\}$

$$
=\left(\lambda_{1}^{2}, \lambda_{2}^{2}, 2 \lambda_{1} \lambda_{2}\right)\left(\begin{array}{c}
\sigma_{G}^{2}(\tilde{\lambda}) \\
\sigma_{N}^{2}(\tilde{\lambda}) \\
\sigma_{\overline{N G}}(\tilde{\lambda})
\end{array}\right)+\lambda_{1}^{2} \sigma_{I}^{2}
$$

$=\left(\lambda_{1}^{2}, \lambda_{2}^{2}, 2 \lambda_{1} \lambda_{2}\right)\left(\begin{array}{ccc}\left(1+\tilde{\lambda}_{1} F\right)^{2} & \tilde{\lambda}_{2}^{2} F^{2} & 2\left(1+\tilde{\lambda}_{1} F\right) \tilde{\lambda}_{2} F \\ \tilde{\lambda}_{1}^{2} F^{2} & \left(1+\tilde{\lambda}_{2} F\right)^{2} & 2\left(1+\tilde{\lambda}_{2} F\right) \tilde{\lambda}_{1} F \\ \left(1+\tilde{\lambda}_{1} F\right) \tilde{\lambda}_{1} F & \left(1+\tilde{\lambda}_{2} F\right) \tilde{\lambda}_{2} F & \left(1+\tilde{\lambda}_{1} F\right)\left(1+\tilde{\lambda}_{2} F\right)+\tilde{\lambda}_{1} \tilde{\lambda}_{2} F^{2}\end{array}\right)\left(\begin{array}{c}\sigma_{G}^{2} \\ \sigma_{N}^{2} \\ \sigma_{N G}\end{array}\right)+\lambda_{1}^{2} \sigma_{i}^{2}$

$=\left(\lambda_{1}+\tilde{\lambda}_{1} F\right)^{2}\left(\sigma_{G}^{2}-\sigma_{N G}\right)+\left(\lambda_{2}+\tilde{\lambda}_{2} F\right)^{2}\left(\sigma_{N}^{2}-\sigma_{N G}\right)+(1+F)^{2} \sigma_{N G}+\tilde{\lambda}_{1}^{2} \sigma_{I}^{2}$ 
Students will minimise this equation under the assumption that

(32) $\frac{d \tilde{\lambda}_{1}}{d \lambda_{1}}=0$

I.e. they do not take into account the relation between the use of predictions and their reliability. Correct minimisation of $\sigma_{p}^{2}$ by use of the information would require to take into account this external effect:

(33) $\frac{d \tilde{\lambda}_{1}}{d \lambda_{1}}=1$

The first order condition for the minimum of the prediction error is:

$$
\text { (34) } \begin{aligned}
& \frac{\partial \sigma_{P}^{2}(\ldots)}{\partial \lambda_{1}}= \\
= & 2 \lambda_{1}(1+F)\left(1+\frac{d \tilde{\lambda}_{1}}{d \lambda_{1}} F\right)\left(\sigma_{G}^{2}-\sigma_{N G}\right)-2 \lambda_{2}(1+F)\left(1+\frac{d \tilde{\lambda}_{1}}{d \lambda_{1}} F\right)\left(\sigma_{N}^{2}-\sigma_{N G}\right)+2 \lambda_{1} \sigma_{I}^{2}=0
\end{aligned}
$$

Solving for $\lambda_{1}$ gives the equilibrium $\lambda_{1}^{*}$ :

$$
\text { (35) } \lambda_{1}^{*}=\frac{\sigma_{N}^{2}-\sigma_{N G}}{\sigma_{G}^{2}-\sigma_{N G}+\sigma_{N}^{2}-\sigma_{N G}+\frac{\sigma_{I}^{2}}{(1+F)\left(1+\frac{\mathrm{d} \tilde{\lambda}_{1}}{\mathrm{~d} \lambda_{1}} F\right)}}
$$

Since $F>0$ it follows immediately that students' $\lambda_{1}^{*}$ (with $\frac{d \bar{\lambda}_{1}}{d \lambda_{1}}=0$ ) is less or equal to the prediction error minimising $\lambda_{1}$ (using $\frac{d \bar{\lambda}_{1}}{d \lambda_{1}}=1$ ).

Figure $\mathrm{V}$ shows the variance of the prediction error, depending on the variance of the additional, public, information according to the optimal use by individual students without taking into account the destabilisation effect $\left(\frac{d \bar{\lambda}_{1}}{d \lambda_{1}}=0\right)$ and according to an optimisation in which the external effects are taken into account $\left(\frac{d \bar{\lambda}_{1}}{d \lambda_{1}}=1\right)$. The figure shows that the prediction error might exceed the prediction error in the case that additional information is not available. 
Figure V: The prediction error depending on the variance of the additional prediction ${ }^{5}$

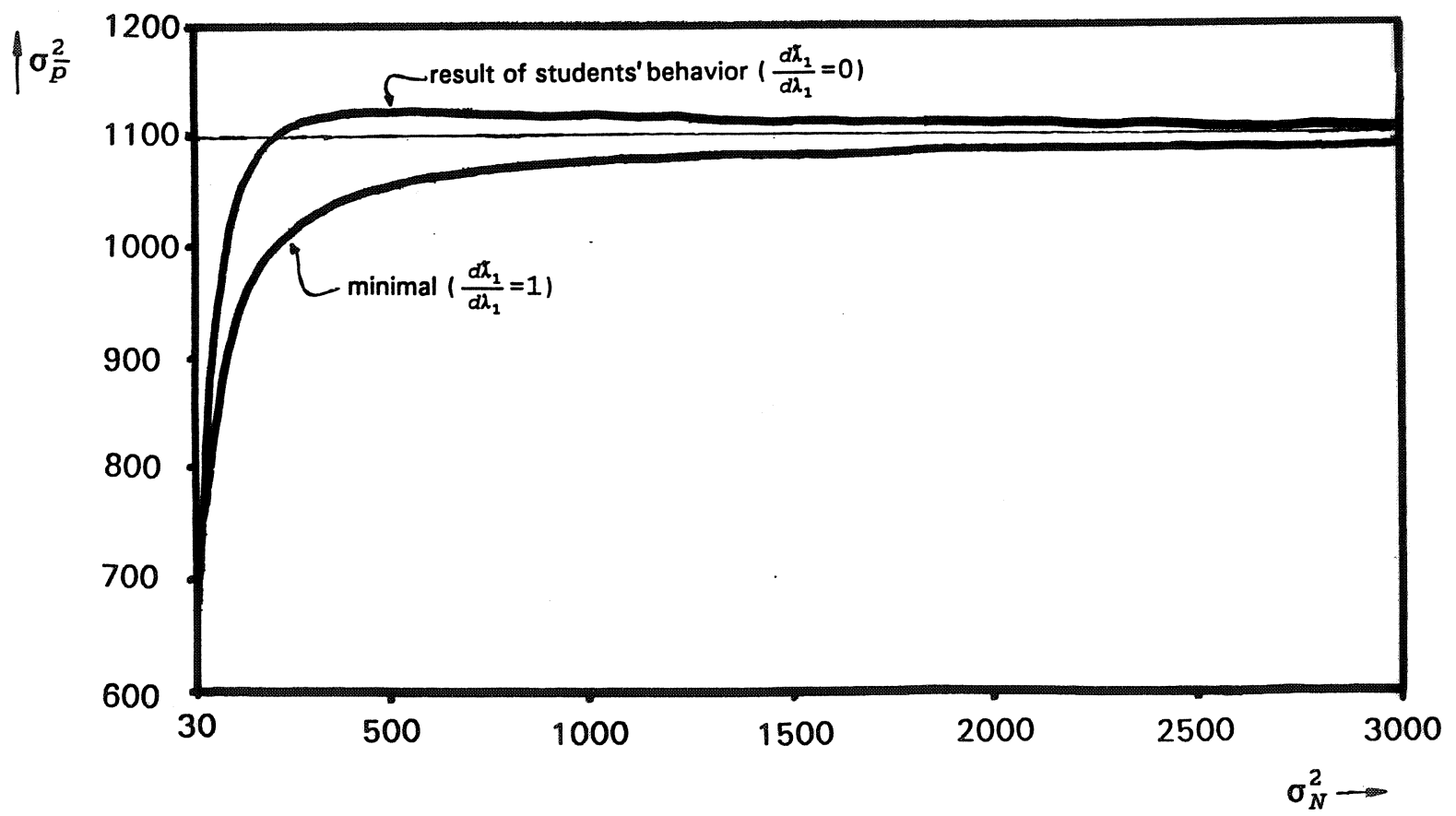

A certain value of $\sigma_{N}^{2}$ leads to a choice of $\lambda_{1}^{*}$ which is smaller than the prediction-error minimising $\lambda_{1}$, i.e. the public information will be used to a 'too large' extent. For certain value's of the parameters a decrease of $\sigma_{N}^{2}$ will lead to an increase of the prediction error, until $\sigma_{N}^{2}$ has reached a certain level at which the quality of the public information compared to the general prediction error without public information is high enough to cause the overusage will improve the prediction error.

As noticed before, the stability of the market only depends on the general prediction error, since only the general prediction error affects the aggregated supply, and thereby the realised wage. The graph in figure $\mathrm{V}$ consists of both individual and general prediction error. In figure $\mathrm{VI}$ the general prediction error is depicted. Multiplying this general prediction error by $\frac{F}{1+F}$ gives the

5. In numerical examples the following figures are used:

$$
\begin{aligned}
& \sigma_{I}^{2}=300 \\
& \sigma_{G}^{2}=50 \\
& \sigma_{N G}=30 \\
& \beta_{S}=2 \\
& \beta_{D}=-6 \\
& \text { so } F=3
\end{aligned}
$$

The figures are chosen in such a way that effects of public information include all possible negative aspects. 
stability of the market.

Figure VI: The general prediction error, i.e. the stability of the market

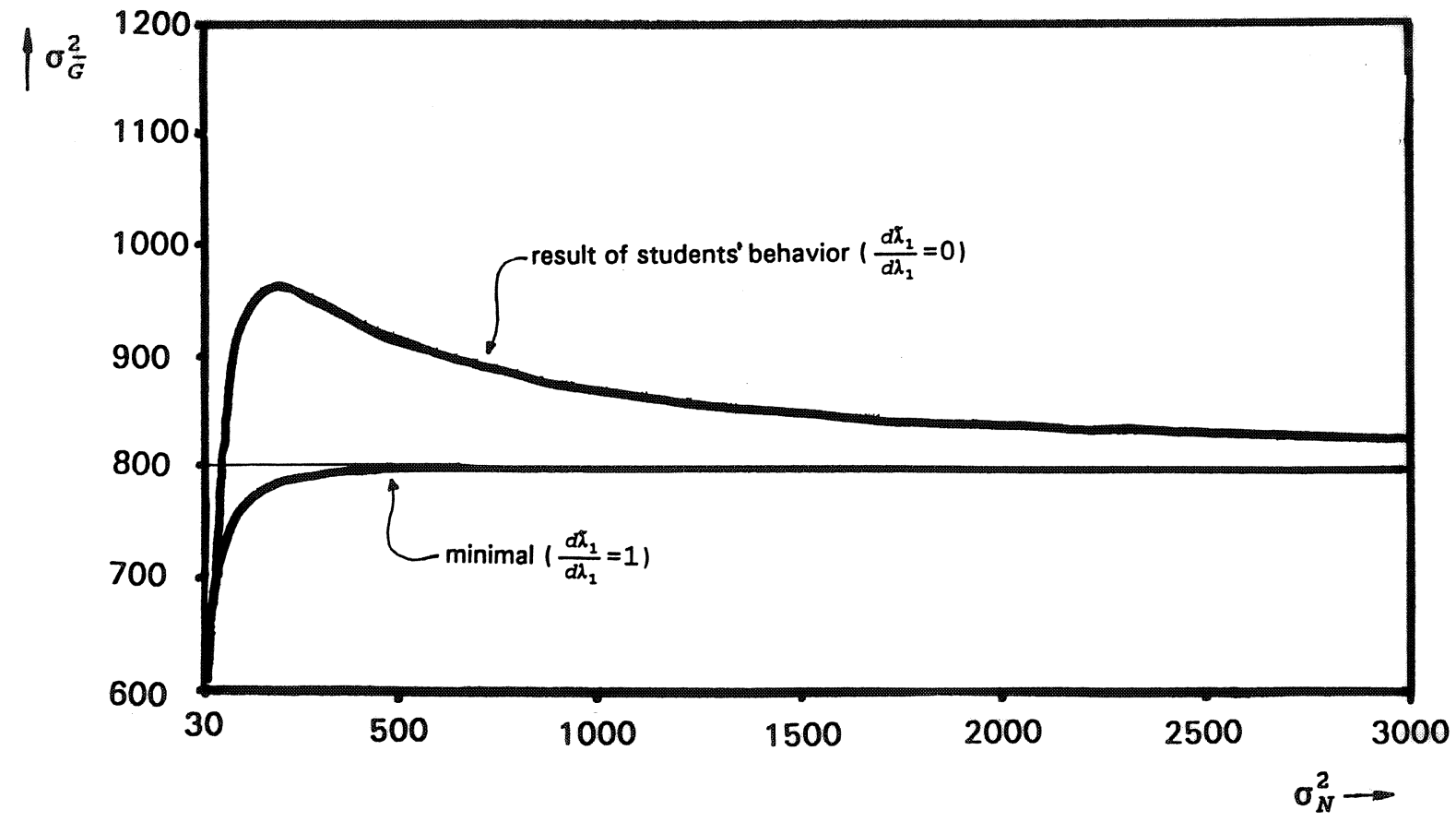

For the stability of the market the inverse effect of a public prediction will be even larger since it does not include $\sigma_{\hat{i}}^{2}$. The individual prediction error will always decrease as the public prediction improves.

Conclusion from this example is that it is not necessary that the provision of additional labour market information makes the market more stable. Conditions for which additional information will increase the stability of the market will be deduced later.

Taking the partial derivatives of the optimal $\lambda_{1}^{*}$ with respect to $\sigma_{N}^{2}$ and $\sigma_{N G}$ leads to:

$$
\begin{aligned}
& \text { (36) } \frac{\partial \lambda_{1}^{*}}{\partial \sigma_{N}^{2}}=\frac{\lambda_{1}^{*} \lambda_{2}^{*}}{\sigma_{N}^{2}-\sigma_{N G}}>0 \\
& \text { (37) } \frac{\partial \lambda_{1}^{*}}{\partial \sigma_{N G}}=\frac{\lambda_{1}^{*}\left(\lambda_{1}^{*}-\lambda_{2}^{*}\right)}{\sigma_{N}^{2}-\sigma_{N G}} \begin{cases}>0 \text { if } \lambda_{1}^{*}>\lambda_{2}^{*} \\
\leq 0 \text { if } \lambda_{1}^{*} \leq \lambda_{2}^{*}\end{cases}
\end{aligned}
$$

The implications of these formula's are very obvious. An increase of the variance of the public prediction will decrease its use and an increase of the covariance between the general prediction and the public prediction will make the use of information more extreme, i.e. if own information was used more than public, the use of public information will further decrease, 
while if public information was used to a greater extent its usage will increase. If the covariance increases the advantage of mixing the two sources will diminish.

\subsection{Welfare effects of additional labour market information}

After these calculations about the usage of additional labour market information we come to the main question of this paper: What are the welfare effects of additional information? This question can be solved by substituting the formula for the usage of additional information (35) into the three cost-functions of section 4 , table 2 .

Before solving these substitutions the reverse question will be answered: If students do not minimise their cost function and if they do not take into account external effects, what function do they minimise?

This question can be solved rather easily. In section 5.1 it is derived that students minimise

(38) $\sigma_{P}^{2}=\left(\lambda_{1}+\tilde{\lambda}_{1} F\right)^{2}\left(\sigma_{G}^{2}-\sigma_{N G}\right)+\left(\lambda_{2}+\tilde{\lambda}_{2} F\right)^{2}\left(\sigma_{N}^{2}-\sigma_{N G}\right)+(1+F)^{2} \sigma_{N G}+\lambda_{1}^{2} \sigma_{I}^{2}$

(equation (31)) with respect to $\lambda_{1}$ under the (false) assumption that $\frac{d \bar{\lambda}_{1}}{d \lambda_{1}}=0$. This leads to:

(39) $\frac{\partial \sigma_{P}^{2}(\ldots)}{\partial \lambda_{1}}=2 \lambda_{1}(1+F)\left(\sigma_{G}^{2}-\sigma_{N G}\right)-2 \lambda_{2}(1+F)\left(\sigma_{N}^{2}-\sigma_{N G}\right)+2 \lambda_{1} \sigma_{i}^{2}$

(see equation (34))

Integrating this derivative gives a function Al with the property that students behave as if they minimise this equation:

$$
\text { (40) } \begin{aligned}
A I & =\int \frac{\partial \sigma_{P}^{2}}{\partial \lambda_{1}} \mathrm{~d} \lambda_{1} \\
& =(1+F)\left(\lambda_{1}^{2} \sigma_{G}^{2}+\lambda_{2}^{2} \sigma_{N}^{2}+2 \lambda_{1} \lambda_{2} \sigma_{N G}\right)+\lambda_{1}^{2} \sigma_{I}^{2}+\text { constant } \\
& =(1+F) \sigma_{\hat{G}}^{2}+\sigma_{\hat{I}}^{2}+\text { constant }
\end{aligned}
$$

This exactly is the total cost function from a welfare-economic point of view (see section 4, table 2). Thus, students behave as if they minimise total costs of the use of information. This is a remarkable result. Firstly, students do not take into account the destabilising effect of their use of public information. They base their decision on the usage of public information on the observed quality of the two sources of information. The quality of the sources itself is 
influenced by their usages.

Apparently, the observed quality of information (with respect to the realisation, thus including the destabilisation effect) transforms the information about the disadvantages of general prediction errors in such a way that students choose a mix $\lambda_{1}^{*}$, which maximises total welfare.

Since the unpredictability of the gap between equilibrium wage and realised wage will influence both students and public prediction, this will not influence students' decision. Furthermore, students do not take into account the redistribution of welfare from themselves to other students and to employers. Redistribution will, however, not influence total welfare what might explain the result.

In general this mix will not minimise other criteria, which have been distinguished before. In table 3 five criteria have been summed up: 1) students welfare, 2) employers welfare, 3) total welfare, 4) the prediction error and 5) the stability of the market. The first column gives the value of $\lambda_{1}$ for which these criteria are optimised. These $\lambda_{1}$ 's will always be ordered like:

(41) $\lambda_{1}^{*}=\lambda_{1}^{\text {total }} \leq \lambda_{1}^{\text {stud }} \leq \lambda_{1}^{\text {pred }} \leq \lambda_{1}^{\text {stab }}$

This means that for the criteria of students welfare, the prediction error and the stability of the market the additional public information is always used to a too great extent.

The second column of table 3 gives the intervals for $\lambda_{1}$ in which the value of the public additional information is non-negative, compared with the situation in which no additional information is used. The lower-bounds of these intervals are ordered the same way as the optimal $\lambda_{1}$ 's.

The third column of the table gives conditions for the value of information to be positive, i.e. it gives conditions for the cases in which the optimal $\lambda_{1}$ with respect to total welfare, which will be chosen, is in this interval.

The implications of the results in table 3 are the following. Although the mix of own predictions and public prediction is not optimal with regard to students welfare, this mix will never cause the value of information for students to be negative. An important condition for this result is that the equilibrium mix is actually used. The results depend on the assumption that students know the quality of their own prediction and the public prediction. 
Table 3: optimal $\lambda_{1}$, non-negative intervals, and conditions for the value of information to be non-negative.

(42) $\left\{\begin{array}{l}\sigma_{I}^{2}<(1+F)\left(\sigma_{G}^{2}-\sigma_{N G}\right) \text { or } \\ \sigma_{N}^{2}-\sigma_{N G}<\frac{\sigma_{I}^{2}+(1+F)\left(\sigma_{G}^{2}-\sigma_{N G}\right)}{\sigma_{I}^{2}-(1+F)\left(\sigma_{G}^{2}-\sigma_{N G}\right)}\left(\sigma_{G}^{2}-\sigma_{N G}\right)\end{array}\right.$

6. Proof in appendix A.

7. The conditions for which additional information decreases the prediction error are cumbersome and do not have an interesting interpretation. Therefore they have been omitted.

8. Proof in appendix B. 
Therefore students need to have a correct estimation of the prediction error of both sources of information. In the next section this assumption will be relaxed, by investigating the effects of an overestimation of the reliability of the public prediction.

The value of information with respect to the total welfare will of course also be positive, because this is what is actually optimised.

Employers welfare, on the other hand, might be negative. This is the case in the situations in which additional information increases the stability of the market. This can be explained by the observation of section 5 that employers welfare increases as the instability of the market increases.

Formula (42) gives the condition which is necessary and sufficient for the market to become more stable as a result of additional labour market information. This stabilisation is assured if (1) the individual component of the prediction error is smaller than the general component, or if (2) the additional information has an prediction error below a certain level. If the public prediction error is smaller than the general component this condition will be fulfilled.

In figure VII the value (or costs) of information depending on its variance is depicted. In fact the relation between the variance of the public forecast and the costs is indirect. The variance influences $\lambda_{1}^{*}$, the extent of usage, and together with this $\lambda_{1}^{*}$ it influences the costs.

Figure VII: The value of information

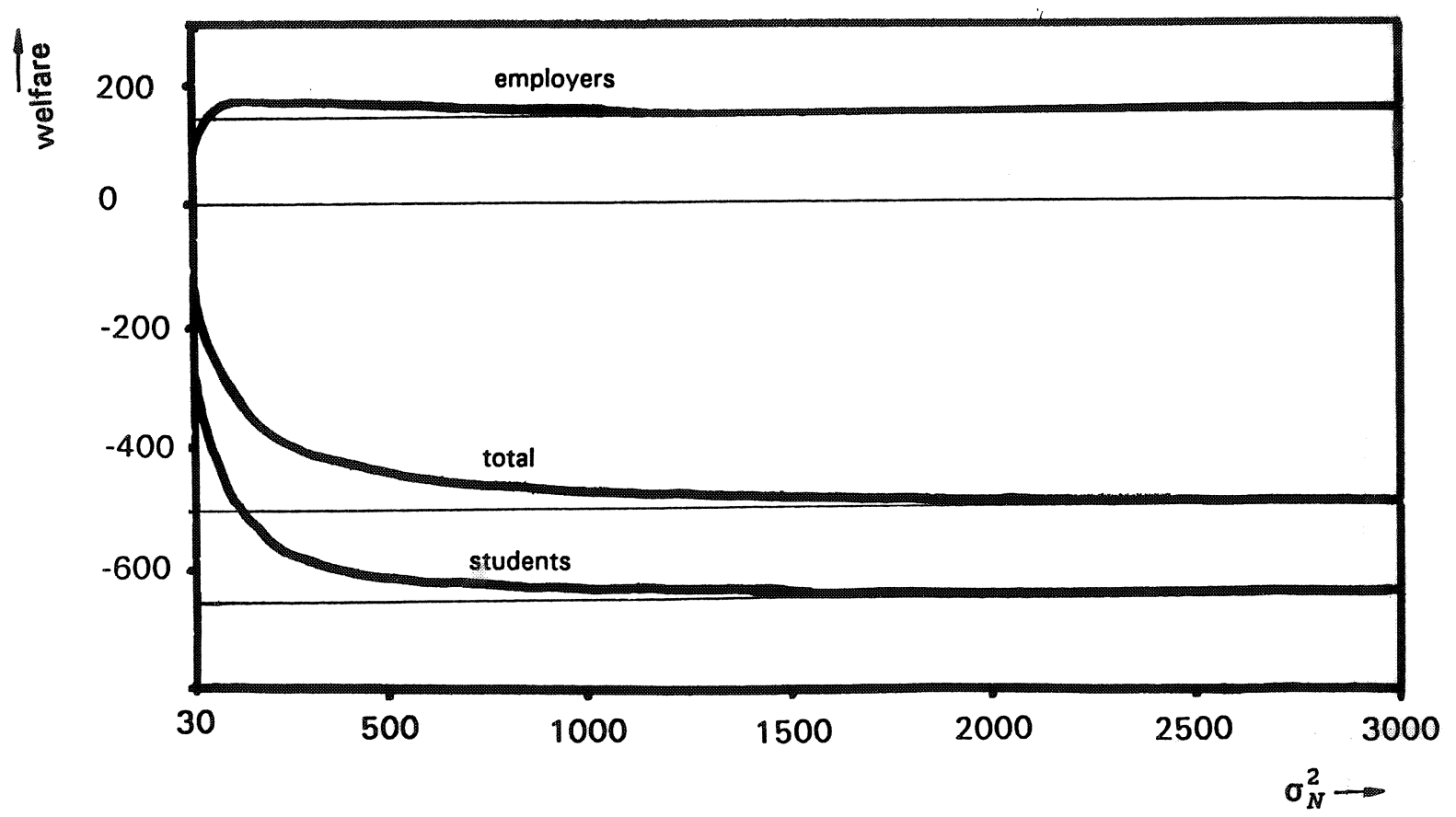




\section{OVERVALUATION OF THE PUBLIC PREDICTION}

All results presented in previous sections depart from the assumption that students know (or correctly estimate) the quality of the public prediction, i.e. they know its variance and its correlation with their own prediction. It is very doubtful whether this is a realistic assumption. In figure VIII the results of the welfare calculations in the case students have a wrong perception of these figures, have been depicted. (In this example they estimate the variance to be half the real variance and they think the covariance to be 0 instead of its real value 30 ).

Figure VIII: Consequences for the welfare effects, due to a misperception of the quality of the public predictions

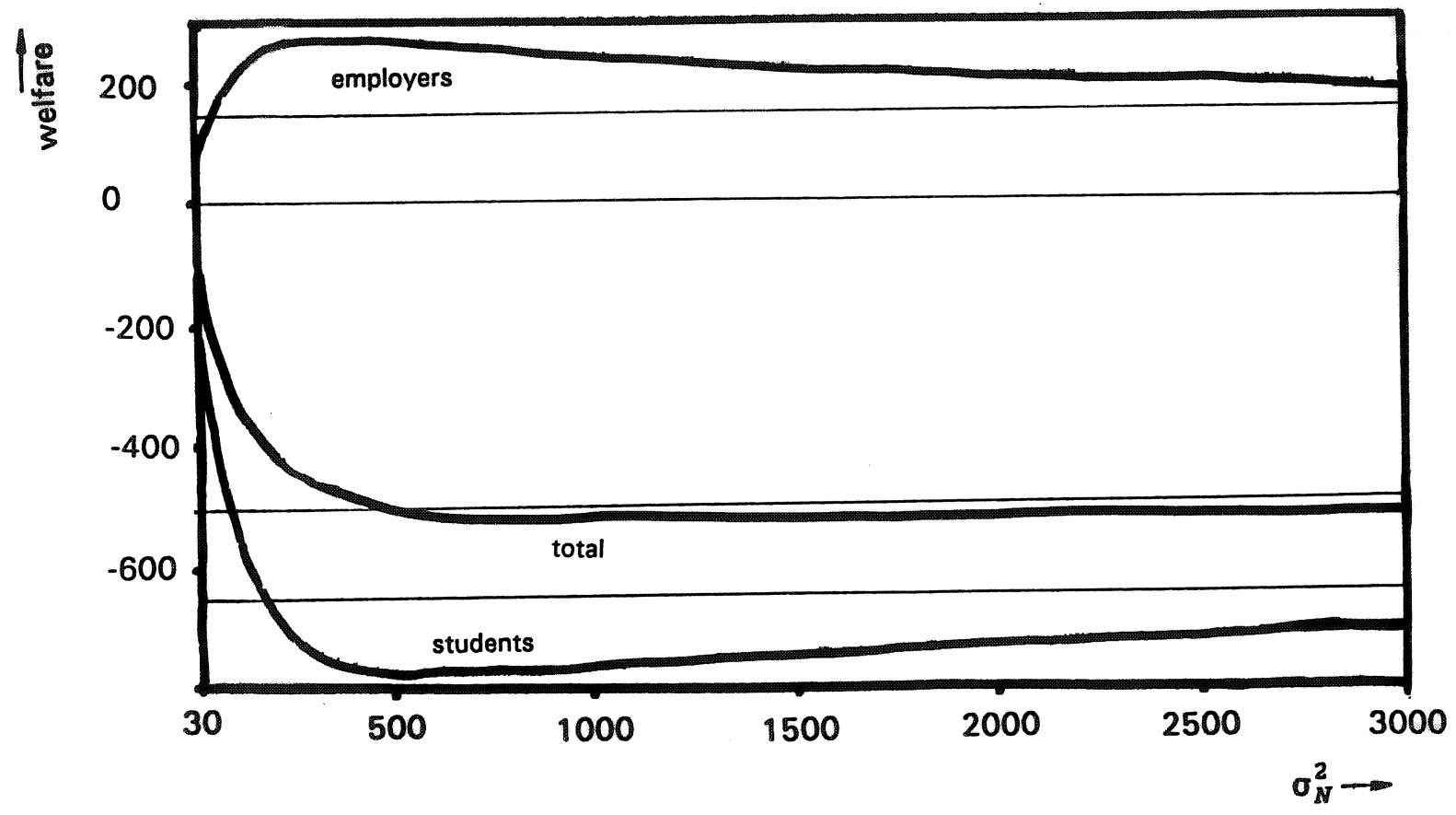

The picture makes immediately clear that the effects of such an overestimation of the reliability of the public prediction might be rather bad. Due to the overestimation of the public prediction students make too much use of this additional information. Therefore the welfare effect of the decrease of dispersion will overwhelm the positive effect of a decrease of the prediction error.

In this section an indicator will be developed to measure the sensitivity of the welfare-results of section 5 to an overestimation of the quality of the public forecast. This indicator consists of two parts. Firstly, the elasticity of $\lambda_{1}^{*}$ with respect to an overvaluation of $\sigma_{N}^{2}$, indicates to what extent behaviour will change as a result of the overvaluation. If $\sigma_{N}^{2}$ will be percepted 
incorrectly, the $\lambda_{1}$ that will be chosen depends on the percepted $\sigma_{N}^{2}$ instead of the real $\sigma_{N}^{2}$. The elasticity indicates the sensitivity of $\lambda_{1}$ for a slight misperception of $\sigma_{N}^{2}$.

Secondly, table 3 gives the interval of $\lambda$ 's for which the total welfare is positive. The ratio between the break-even $\lambda_{1}$ at which the welfare effect is exactly 0 , and the optimal $\lambda_{1}^{*}$ provides an indication of the maximum relative change in $\lambda_{1}$ (due to misperception) for which the welfare effect remains positive.

In section 5 (equation (36)) the partial derivative of $\lambda_{1}$ with respect to $\sigma_{N}^{2}$ has been calculated. Rewriting this derivative as an elasticity gives:

(43) $\frac{\left(\frac{\partial \lambda_{1}^{*}}{\partial \sigma_{N}^{2}}\right)}{\left(\frac{\lambda_{1}^{*}}{\sigma_{N}^{2}-\sigma_{N G}}\right)}=\lambda_{2}^{*}$

With the use of the non-negativity interval of table 3 the ratio between the $\lambda_{1}$ for which total welfare is exactly zero and $\lambda_{1}^{*}$, which optimises total welfare can be calculated:

(44) $\frac{\lambda_{1}^{\text {b.e. }}}{\lambda_{1}^{*}}=\frac{\sigma_{N}^{2}-\sigma_{G}^{2}-\frac{\sigma_{I}^{2}}{1+F}}{\sigma_{N}^{2}-\sigma_{N G}}=2-\frac{1}{\lambda_{1}^{*}}$

Figure IX: The derivative of $\lambda_{1}$ with respect to $\sigma_{N}^{2}$

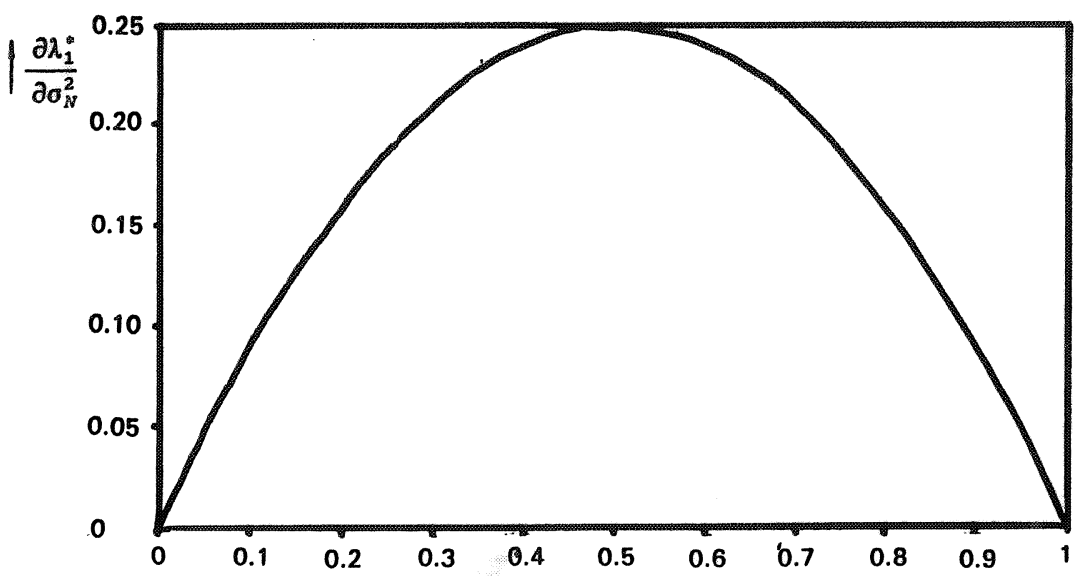


Figure $X:$ The break-even ratio

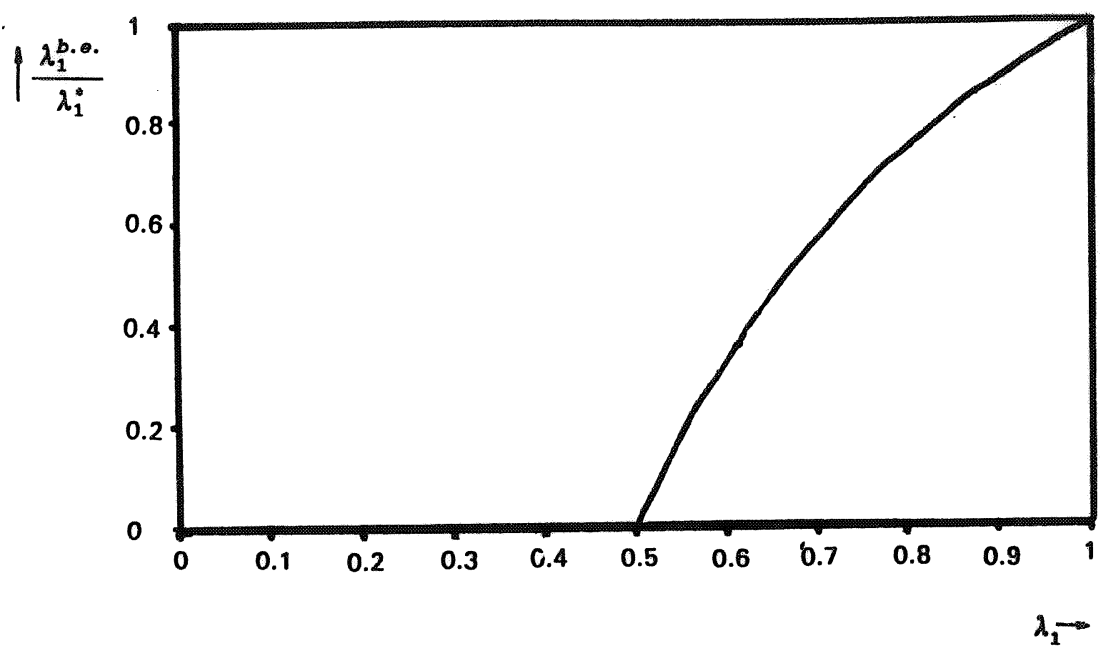

The derivative of $\lambda_{1}^{*}$ (equation(36)) and the ratio between the break-even and the optimal $\sigma_{N}^{2}-\sigma_{N G}$ are graphed in figure IX and X. Figure IX shows that if $\lambda_{1}^{*}<\frac{1}{2}$ total welfare can not be negative as a result of a misperception. The risk of a misperception will be large if the derivative is large, i.e. a small misperception leads to a relative large change in $\lambda_{1}$, and will be large if the gap between optimal and break-even $\lambda_{1}$ is small, i.e. if the ratio in (44) is large. The riskindicator, i.e. the product of the elasticity and the break-even-ratio is:

(45) RISK $=\lambda_{2}^{*}\left(2-\frac{1}{\lambda_{1}^{*}}\right)$

Figure $\mathrm{XI}$ shows this 'risk'. Its maximum is reached at $\lambda_{1}^{*}=\sqrt{2} \approx 0.707$.

FIGURE XI: The 'risk of misperception'

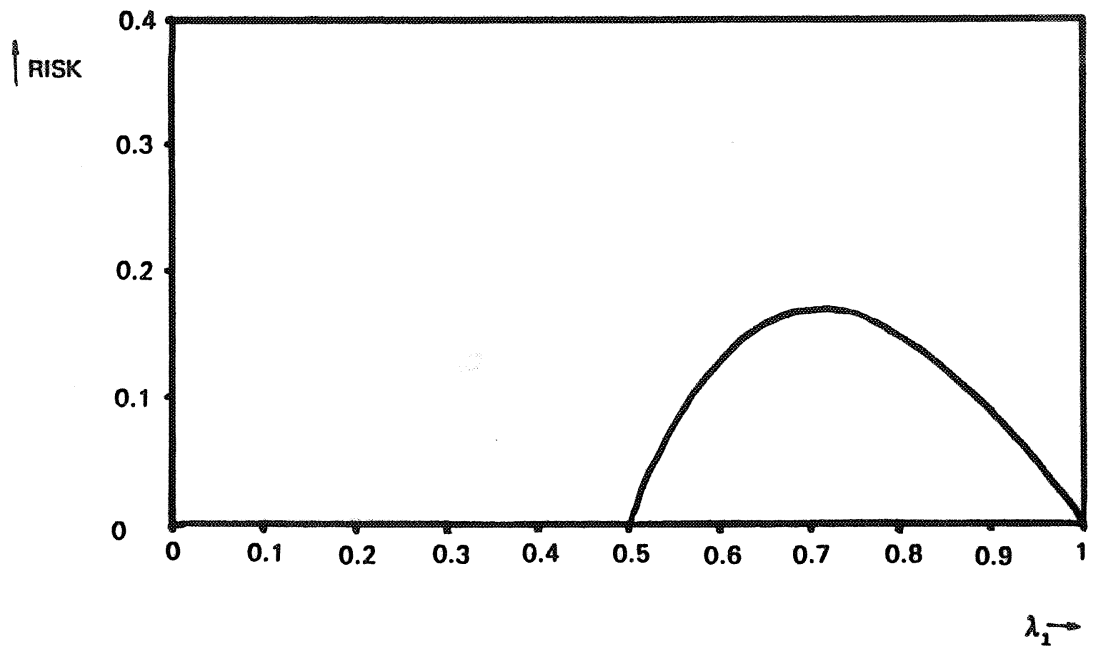


Figure XII shows that the risk of a negative value of public information due to a misperception of its quality is relatively high if the variance of the public information is slightly less than the variance of individual students. In this situation the public forecasts will still be used substantially, while its reliability is relatively low. Such a low quality forecast might be very useful, but only in the case when it is used the right way. If its quality further diminishes its use will also decrease, what will decrease its risk.

This risk-measure indicates that it is very important to report together with a public prediction its quality. Since it is not unlikely that many public predictions do not really dominate individual predictions by variance, most part of their value comes from the combination of individual and public prediction which makes necessarily a correct valuation of both sources. 


\section{CONCLUSIONS}

The aim of this paper was to investigate the effects of public labour market information on the welfare of students and employers, and its relation with the stability of the market in the case students' predictions are dispersed.

In a model in which predictions are not dispersed a public prediction simply decreases the variance of the prediction error, which implies a welfare gain for students and a welfare loss for employers. The gain of the students exceeds the loss of the employers, so in total there is a gain, which is, however, accompanied with a redistribution of welfare, from employers to students. Due to this redistribution, it is not in the interest of the employers as a group to support a public prediction programme. It will of course be the interest of some employers, who face a shortfall in labour the next years, to inform students, but this signal might be unreliable since it will be in the interest of every employer to suggest a shortfall.

In the case students' predictions are dispersed, the relation between public information and the stability of the market becomes less evident. Providing a public forecast will lead to a decrease of individual prediction errors, but also will make students predictions more correlated. Since the public prediction is the same for everybody, students will, if they use the public prediction, base their predictions on the same source. An error in the public prediction will influence everyone's prediction the same way, while in the case where predictions were more dispersed errors might compensate each other on an aggregated level.

Under the assumption that students behave optimally, students will overestimate the importance of general prediction errors. Since prediction errors that are made by everyone influence the market, they seem to be worse than similar individual prediction errors.

When using public predictions students will not take into account that the reliability of a forecast depends on its use. If students are going to make more use of one source this change in behaviour will influence the reliability of all sources.

Furthermore, for individual students there is no difference between individual and general prediction errors, while the use of public information transforms individual prediction errors into general prediction errors. These 'external effects' are not taken into account by students.

Despite, these external effects the investigation of optimisation behaviour of students leads to the remarkable conclusion that students behave as if they optimise total welfare. Optimising 
total welfare does, however, not coincide with minimising the stability of the market any more. Under certain conditions, a public prediction might lead to an increase of the instability of the market (see condition (42)). This is, however, not a negative point. Public information, in this case, increases the market instability which has a negative welfare effect, but decreases individual uncertainty which has a positive welfare effect. In total the effect will always be positive if information is used optimally.

Finally, this assumption that students use public information optimally is dropped. This leads to a situation in which the value of public information might decrease drastically, and even might become negative. Most of all in a situation in which public information does not really dominate individual predictions in variance, it is very important that students are able to estimate its value. If, on the other hand, the public prediction is better than the individual predictions, there is no risk for negative effects on total welfare due to misperception. 


\section{REFERENCES}

Antonovitz, F. and T. Roe (1986), 'A Theoretical and Empirical Approach to the Value of Information in Risky Markets'. Review of Economics and Statistics 68, pp. 105-114.

Borghans, L. (1990), 'The Value of Public Labour Market Information and the Stability of the Market'. ROA-W-1990/6E, Maastricht.

Bradford, D.F. and H.H. Kelejian (1977), 'The Value of Information for Crop Forecasting in a Market System: Some Theoretical Issues'. Review of Economic Studies 59. pp. 519531.

Freebairn, J.W. (1976), 'The Value and Distribution of the Benefits of Commodity Price Outlook Information'. The Economic Record, pp. 199-212.

Freebairn, J.W. and G.A. Withers (1979), 'Welfare Effects of Salary Forecasts Error in Professional Labour Markets'. The Review of Economics and Statistics 61, pp. 234-241.

Freeman, R.B. (1971), The Market for College-Trained Manpower. Cambridge (Mass.).

Hayami, Y. and W. Peterson (1975), 'Social Returns to Public Information Cervices: Statistical Reporting of U.S. Farm Commodities'. The American Economic Review 52. pp 119-130.

Kodde, D.A. (1985), Microeconomic Analysis of Demand for Education. Rotterdam.

Massel, B.F. (1969), 'Price Stabilization and Welfare'. Quarterly Journal of Economics 88, pp. 284-298.

Turnovski, S.J. (1978), 'Stabilization Rules and the Benefits from Price Stabilization'. Journal of Public Economics 9, pp. 37-57.

Waugh, F.V. (1944), 'Does the Consumer Benefit from Price Instability?' Quarterly Journal of Economics 63, pp. 602-614. 


\section{APPENDIX A}

Proof of the non-negativity of the value of information with respect to students welfare:

$$
\begin{aligned}
\lambda_{1}^{*} & =\frac{\sigma_{N}^{2}-\sigma_{N G}}{\sigma_{N}^{2}+\sigma_{G}^{2}-2 \sigma_{N G}+\frac{\sigma_{I}^{2}}{1+F}} \\
& \geq \frac{\sigma_{N}^{2}-\sigma_{N G}-\frac{\sigma_{I}^{2}}{1+2 F}}{\sigma_{N}^{2}+\sigma_{G}^{2}-2 \sigma_{N G}+\frac{\sigma_{I}^{2}}{1+F}-\frac{\sigma_{I}^{2}}{1+2 F}} \\
& \geq \frac{\sigma_{N}^{2}-\sigma_{N G}-\frac{\sigma_{I}^{2}}{1+2 F}}{\sigma_{N}^{2}+\sigma_{G}^{2}-2 \sigma_{N G}+\frac{2 \sigma_{I}^{2}}{1+2 F}-\frac{\sigma_{I}^{2}}{1+2 F}} \\
& \geq \frac{\sigma_{N}^{2}-\sigma_{G}^{2}-\frac{\sigma_{I}^{2}}{1+2 F}}{\sigma_{N}^{2}+\sigma_{G}^{2}-2 \sigma_{N G}+\frac{\sigma_{I}^{2}}{1+2 F}}
\end{aligned}
$$

what is the lower-bound of the interval (table 3 ) for which the value of information with respect to students' welfare is non-negative $\square$. 


\section{APPENDIX B}

Proof of condition (42) for which additional information increases the stability of the market:

$$
\begin{aligned}
& \frac{\sigma_{N}^{2}-\sigma_{N G}}{\sigma_{N}^{2}+\sigma_{G}^{2}-2 \sigma_{N G}+\frac{\sigma_{I}^{2}}{1+F}}>\frac{\sigma_{N}^{2}-\sigma_{G}^{2}}{\sigma_{N}^{2}+\sigma_{G}^{2}-2 \sigma_{N G}} \Longleftrightarrow \\
& \left(\sigma_{N}^{2}-\sigma_{N G}\right)^{2}+\left(\sigma_{N}^{2}-\sigma_{N G}\right)\left(\sigma_{G}^{2}-\sigma_{N G}\right) \\
& \quad>\left(\sigma_{N}^{2}-\sigma_{N G}\right)^{2}+\left(\sigma_{N}^{2}-\sigma_{N G}\right)\left(\sigma_{G}^{2}-\sigma_{N G}\right)+\frac{\left(\sigma_{N}^{2}-\sigma_{N G}\right) \sigma_{I}^{2}}{1+F} \\
& \quad-\left(\sigma_{N}^{2}-\sigma_{N G}\right)\left(\sigma_{G}^{2}-\sigma_{N G}\right)-\left(\sigma_{G}^{2}-\sigma_{N G}\right)^{2}-\frac{\left(\sigma_{G}^{2}-\sigma_{N G}\right) \sigma_{I}^{2}}{1+F} \Longrightarrow \\
& \frac{\left(\sigma_{N}^{2}-\sigma_{N G}\right) \sigma_{I}^{2}}{1+F}-\frac{\left(\sigma_{G}^{2}-\sigma_{N G}\right) \sigma_{I}^{2}}{1+F}-\left(\sigma_{N}^{2}-\sigma_{N G}\right)\left(\sigma_{G}^{2}-\sigma_{N G}\right)-\left(\sigma_{G}^{2}-\sigma_{N G}\right)^{2}<0 \\
& \left(\sigma_{N}^{2}-\sigma_{N G}\right)\left(\frac{\sigma_{I}^{2}}{1+F}-\left(\sigma_{G}^{2}-\sigma_{N G}\right)\right)<\frac{\left(\sigma_{G}^{2}-\sigma_{N G}\right) \sigma_{I}^{2}}{1+F}+\left(\sigma_{G}^{2}-\sigma_{N G}\right)^{2} \Longrightarrow \\
& \left\{\begin{array}{c}
\sigma_{I}^{2}<(1+F)\left(\sigma_{G}^{2}-\sigma_{N G}\right) \quad \text { or } \\
\sigma_{N}^{2}-\sigma_{N G}^{<} \frac{\sigma_{I}^{2}+(1+F)\left(\sigma_{G}^{2}-\sigma_{N G}\right)}{\sigma_{I}^{2}-(1+F)\left(\sigma_{G}^{2}-\sigma_{N G}\right)}\left(\sigma_{G}^{2}-\sigma_{N G}\right)
\end{array}\right.
\end{aligned}
$$

